Meteorological variation in daily travel behaviour: evidence from revealed preference data from the Netherlands

Peer-reviewed author version

CREEMERS, Lieve; WETS, Geert \& COOLS, Mario (2015) Meteorological variation in daily travel behaviour: evidence from revealed preference data from the Netherlands. In: THEORETICAL AND APPLIED CLIMATOLOGY, 120 (1-2), p. 183-194.

DOI: $10.1007 / \mathrm{s} 00704-014-1169-0$

Handle: http://hdl.handle.net/1942/18810 


\section{METEOROLOGICAL VARIATION IN DAILY TRAVEL BEHAVIOUR: EVIDENCE FROM REVEALED-PREFERENCE DATA FROM THE NETHERLANDS}

\author{
Lieve Creemers ${ }^{1}$, Geert Wets ${ }^{1}$, and Mario Cools ${ }^{2}$ \\ ${ }^{1}$ Transportation Research Institute (IMOB) \\ Hasselt University \\ Wetenschapspark 5, bus 6 \\ B-3590 Diepenbeek \\ Belgium \\ ${ }^{2}$ Local Environment Management \& Analysis (LEMA) \\ Université de Liège \\ Chemin des Chevreuils 1, Bât. 52/3 \\ BE-4000 Liège \\ Belgium \\ Corresponding author: Mario Cools \\ Email: mario.cools@ulg.ac.be \\ Tel.: +32 485427155 \\ Fax.: +32 34857591
}




\section{INTRODUCTION}

Weather has a variety of effects on transportation systems; most studies focus on the impact of weather on network performance (Cools et al., 2010a; Habtemichael et al., 2012; Kwon et al., 2013), including traffic safety (Ahmed, 2012; Jung and Noyce, 2012; Vlahogianni et al., 2012), traffic speeds (Sabir et al. 2011; Zhao et al. 2012; Hooper et al. 2013) and maintenance costs (Hammond et al., 2010; Venner and Zamurs, 2012; Rowan et al., 2013). In contrast, the effect of weather on the daily travel behaviour of individuals has received much less attention. Moreover, the majority of these studies have focused on weather extremes such as snow, thunderstorm, extreme hot and extreme cold temperatures (Cools et al., 2010b); less attention has been paid to the effects of normal, everyday weather conditions (Böcker et al., 2013a). A recent literature review by Böcker et al. (2013a) provides an overview of the existing understanding of the impact of everyday weather conditions on individual travel behaviour. Hart and Sailor (2009) focused on the reverse relationship, namely, the impact of the transportation system on the local weather environment, and particularly the effect on temperature. They found that temperatures along arterial roads differ by up to $1.3^{\circ} \mathrm{C}$ on weekdays versus weekends, due to higher weekday traffic densities.

Within the Belgian-Dutch research context, the impact of weather on daily activity-travel behaviour has been investigated most frequently from the perspective of modal choices, especially in terms of the use of non-motorised modes. Van Cauwenberg et al. (2012) highlighted the significant influence of various environmental factors, including weather, on walking behaviour, based on walkalong interviews. Thomas et al. (2013) explored the influence of weather on cycling by investigating bicycle flows and concluded that up to $80 \%$ of the variation in cycling demand could be attributed to weather conditions. In order of importance, average temperature, sunshine duration, precipitation duration and wind speed were found to significantly affect cycling demand. Heinen et al. (2011) assessed the effect of five weather conditions on cycling behaviour and concluded that both the quantity and duration of rain affect cycling negatively. They also noted that the inclination to cycle decreases in proportion to increases in wind speed. Lastly, they concluded that increases in sunshine duration and temperature increase the probability that commuters will cycle. Bos et al. (2004) compared the use of park-and-ride facilities to car use and door-to-door public transport using a choice experiment and concluded that park-and-ride is preferred to both car use and door-to-door public transport in adverse weather conditions.

Extending the scope beyond modal choices, Kusumastuti et al. (2010) showed that in the context of fun-shopping, weather is a crucial contextual aspect, especially in timing and mode choice decisions. With respect to commuting trips, Khattak and De Palma (1997) demonstrated the effect of adverse weather conditions on the propensity of individuals to change their travel behaviour, i.e., mode, route and departure time changes. A more elaborate experiment that assessed changes in activity-travel behaviour in response to adverse weather conditions was carried out by Cools et al. (2010b). In their study, the significance of cold temperatures, warm temperatures, and the occurrence of snow, rain, fog, and storms was confirmed. They also highlighted the dependence of the behavioural adjustments on the trip purpose.

With respect to weather information, Khattak and De Palma (1997) noted that close to $75 \%$ of Brussels commuters kept themselves informed about weather through secondary information sources such as radio and television. With respect to the effect of weather information, Cools and Creemers (2013) discussed the dual role of weather forecasts in changes in daily activity-travel behaviour: on the one hand, forecasted weather conditions significantly affect the probability that individuals will change their travel plans; on the other hand, different methods of acquiring weather information (exposure, media sources, or perceived reliability) do not affect the probability of behavioural adaptations.

An assessment of revealed-preference data stemming from the 1996 Dutch national household travel survey (NHTS) showed that snow is the only weather variable that reduces trip speed (Sabir et al., 2011). Sabir et al. (2011) also concluded that, given the impact of weather on speed and thus on travel times, weather should be considered as one of the determinants of accessibility. Using NHTS data to forecast the effect of climate change, Böcker et al. (2013b) projected that under 2050 climate conditions, compared to travel behaviour under present climate conditions, increased use and distance travelled will be recorded for open-air transport modes, mainly at the expense of the car. 
This study contributes to the weather-related transport literature by investigating the meteorological variation in revealed-preference travel data. Acquiring insights in daily travel behaviour under adverse weather conditions is important in the context of mobility management. Nonetheless, traffic analysis tools assume ideal conditions and do not take into account the uncertainties in demand and supply caused by (adverse) weather conditions (Lam et al., 2008). To meet the need of policy makers to make better long-term decisions, more accurate estimates of travel demand in traffic simulations are needed. Consequently, there is a trend toward incorporating more realistic travel behaviour in dynamic network models (Khattak and De Palma, 1997). Hence, the main objective of this study was to investigate the impact of weather conditions on revealed activity participation (trip motives) and revealed modal choices in the Netherlands. To this end, individual trip information was linked to hourly and daily meteorological information. A description of the information concerning the travel behaviour data and associated weather information is provided in the next section, complemented with an outline of the methodology in Section 3. Consequently the results are presented in Section 4, and a discussion of the results and a conclusion are provided in Section 5.

\section{DATA}

\subsection{Revealed-Preference Data: Dutch NHTS 2008}

The data on daily travel behaviour were derived from the Dutch NTHS 2008 survey, known as MON2008 (Mobility Research of the Netherlands) (Projectteam Mon, 2008). Among the variety of surveys conducted in the Netherlands, MON provides the largest and most comprehensive set of travel data. The MON 2008 dataset contains information on 18,102 households, including data from household questionnaires, personal questionnaires and travel diaries (Projectteam Mon, 2008). As documented by Projectteam MON (2008), the response rate of the survey was 70.3\%. Of particular interest to this study are the trip motives and the modal choices indicated in the trip diaries. The influences of various weather conditions on these two outcome variables were investigated. While analysis of the relationship between weather and modal choice is a logical choice, analysis of the relationship between trip motive and weather is less obvious. The motivation for this analysis lies in the fact that behavioural responses to weather conditions, in terms of alterations of activity types, correspond to an altered probability of undertaking a trip for the corresponding trip motive.

For the purposes of the analyses described in this study, the main trip motives (i.e., activity purposes) were subdivided into commuting (work/school), shopping, leisure, visits and other (e.g., bring/get) categories. The distribution of the 120,770 trips according to these trip motives is displayed in Table 1. A relatively homogenous distribution across the various trip motives is evident.

The main transport modes were subdivided into four categories. The first category pertains to car users, including both car drivers and car passengers. The second category pertains to vulnerable road users, i.e., cyclists, moped riders and pedestrians. The third category consists of travellers by train, bus, tram or underground, grouped together under the heading of public transport users. The fourth category pertains to other transport modes, such as motorbikes, company/school bus services, cabs, etc. Table 1 shows that car travel and non-motorised travel are the most popular modal choices.

TABLE 1 Distribution of trips by trip motive and modal choice

\begin{tabular}{|l|l|r|}
\hline Parameter & Category & Percentage \\
\hline \multirow{4}{*}{ Trip motive } & Commuting & 27.53 \\
\cline { 2 - 3 } & Shopping & 24.33 \\
\cline { 2 - 3 } & Leisure & 22.21 \\
\cline { 2 - 3 } & Visits & 14.07 \\
\cline { 2 - 3 } & Other & 11.86 \\
\hline \multirow{4}{*}{ Modal choice } & Car & 47.93 \\
\cline { 2 - 3 } & Public transport & 4.70 \\
\cline { 2 - 3 } & Non-motorised modes & 45.86 \\
\cline { 2 - 3 } & Other & 1.51 \\
\hline
\end{tabular}


To confirm that the effects of weather conditions on trip purpose and mode choice are indeed associated with weather conditions rather than other factors, a multitude of socio-demographic variables were also taken into account. Furthermore, to guarantee optimal correspondence between the sample and the population, weights were used to correct for sample bias and sampling errors. These weights were determined by matching the distribution of variables in the sample with the corresponding distribution in the population statistics.

\subsection{Weather Data}

The weather data used in the study were provided by the Royal Dutch Meteorological Institute (Projectteam Mon, 2008). These data included hourly weather data for the data collection period of MON2008 and were available for 36 weather stations in the Netherlands (see Figure 1 for the geographic distribution of these weather stations). The following types of hourly data are available: mean wind speed (in $0.1 \mathrm{~m} / \mathrm{s}$ ), temperature (in $0.1^{\circ} \mathrm{C}$ ) at $1.50 \mathrm{~m}$, sunshine duration (in 0.1 hour), precipitation duration (in 0.1 hour), cloud cover (in octants), fog formation (yes/no), snowfall (yes/no), thunderstorm (yes/no), and ice formation (yes/no).

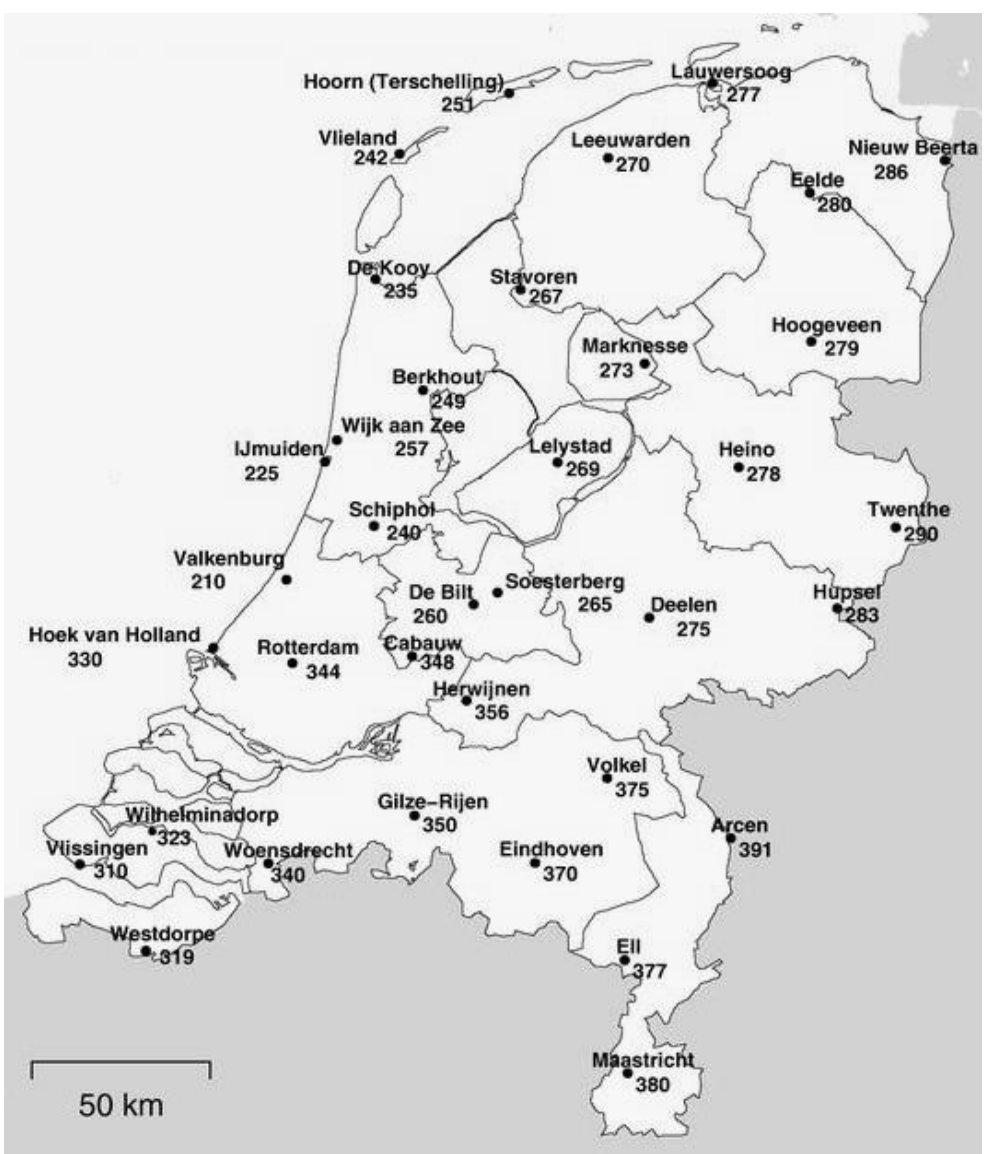

FIGURE 1 Locations of the meteorological stations (Sluijter et al., 2011).

A better understanding of how frequently these weather events occur in the Netherlands is provided by various weather-related measures displayed in Table 2. It is worth mentioning that the Netherlands have a moderate maritime climate with mild winters and fresh summers.

To facilitate data matching between the weather data and the travel data, each Dutch municipality was matched with the nearest weather station. When some data for a weather station were missing, data from the second-nearest weather station were used. In this way, it was possible to link the weather information with the trip data by relating the weather data to the municipalities of origin of the trips. A basic description of the results of this data matching process is provided in Table 3 . The labels are used to refer to the various weather variables in the remainder of the paper. This table 
provides an overview of the occurrence of various weather conditions during the multitude of trips that were recorded in MON2008.

Note that the extreme weather events, such as ice formation, thunderstorms, and snowfall are very infrequent, which is consistent with the averages reported in Table 2.

TABLE 2 Weather parameters measured by De Bilt (The Netherlands) (Sluijter et al. 2011)

\begin{tabular}{|l|r|r|r|}
\hline Parameter & $\mathbf{2 0 0 8}$ & $\mathbf{2 0 0 9}$ & Normal $^{1}$ \\
\hline Air pressure (reduced to sea level) & 1014.5 & 1014.1 & 1015.5 \\
\hline Average wind speed $(\mathrm{m} / \mathrm{s})$ & 3.6 & 3.4 & 3.3 \\
\hline Sunshine duration $(\mathrm{h})$ & 1735 & 1838 & 1524 \\
\hline Average temperature $\left({ }^{\circ} \mathrm{C}\right)$ & 10.6 & 10.5 & 9.8 \\
\hline Average maximum temperature & 14.6 & 14.5 & 13.9 \\
\hline Average minimum temperature & 6.5 & 6.2 & 5.8 \\
\hline Absolute maximum temperature & 30.7 & 33.8 & 30.6 \\
\hline Absolute minimum temperature & -8.6 & -11.1 & -10.1 \\
\hline Number of freezing days $\left(\min <0^{\circ} \mathrm{C}\right)$ & 55 & 56 & 58 \\
\hline Number of wintry days $\left(\max <0^{\circ} \mathrm{C}\right)$ & 3 & 9 & 8 \\
\hline Number of summery days $\left(\max \geq 25^{\circ} \mathrm{C}\right)$ & 26 & 27 & 22 \\
\hline Number of heat wave days $\left(\mathrm{max} \geq 30^{\circ} \mathrm{C}\right)$ & 1 & 1 & 3 \\
\hline Average relative atmospheric humidity $(\%)$ & 81.4 & 80.5 & 81.9 \\
\hline Total precipitation $(\mathrm{mm})$ & 881 & 777 & 793 \\
\hline Number of days with measurable precipitation $(\geq 0.1 \mathrm{~mm})$ & 199 & 180 & 186 \\
\hline Number of days with thunderstorm & 37 & 33 & 32 \\
\hline Number of days with snow & 18 & 28 & 25 \\
\hline Number of days with fog & 95 & 87 & 65 \\
\hline
\end{tabular}

${ }^{1}$ Normal: long-term meteorological average (1971-2000)

One could observe from Table 3 that the individual weather conditions were complemented with a number of thermal indices that represent the effect of thermal comfort. These indices express the conjoint effect of different weather variables on which the indices are built. In particular, the heat index, the effective temperature, the wet-bulb globe temperature, the apparent temperature, physiologically equivalent temperature (PET), and the universal thermal climate index (UTCI) as defined in Blazejczyk et al. (2012) were calculated. Note that the following weather variables on which these thermal indices are based - i.e. air temperature, relative humidity, and wind speed - are not tabulated and included in the analyses to overcome problems of multicollinearity (two or more predictor variables being highly correlated). After all, in regression models it explicitly assumed that that the predictor variables are uncorrelated. The indices derived from heat budget models, i.e. the physiologically equivalent temperature (PET) and the universal thermal climate index (UTCI) are calculated using the standards and default values used in RayMan 1.2 (Matzarakis et al., 2010) and BioKlima 2.6 (Blazejczyk, 2010), as the underlying attributes such as clothing type (clothing insulation) and body mass (needed for the calculation of metabolic rate) are not recorded in national travel surveys. Although, some caution is needed in the interpretation of the effect of these thermal indices, since clothing type and body mass directly influence activity type and modal choice (Wong et al., 2011; Heinen et al., 2013; Zick et al., 2013), as the consideration of standard and default values for these variables might to some extent confound the parameter estimates of these thermal indices, consideration of heat balance based indices in addition to or as preferred alternative to simple indices, is strongly recommended. Blazejczyk et al. (2012) concluded that the application of a complete heat budget model is required to correctly characterize the thermo-physiological impact of weather.

Besides, the complementation with thermal indices, the seasonality of the weather conditions has been incorporated by variables reflecting whether or not the meteorological condition occurred for the first time in 7 albeit 30 days. This way seasonal habituation of severe weather is taken into account. Furthermore, the scope of the weather variables in terms of occurrence during the day has been extended in two ways. A first variable indicates whether the weather condition occurred earlier the day of recording. Second, the daily amount/duration of the weather condition until the recorded hour is calculated. 
In summary, the thermal comfort conditions, as well as the aesthetical and physical aspects of weather are considered to analyse the impact of weather on daily travel behaviour. This is in line with current research efforts that assess the meteorological influences on holiday/tourism travel (Çalışkan et al., 2012; Matzarakis et al., 2013).

TABLE 3 Data description of the weather conditions during the MON2008 trips.

\begin{tabular}{|c|c|c|}
\hline Parameter & Label & Basic statistics \\
\hline \multicolumn{3}{|l|}{ Thermal components } \\
\hline Effective temperature $(\mathrm{ET})^{5}$ & ET & Mean: 1.67, Std. Dev.: 8.68 \\
\hline Wet-bulb globe temperature (WBGT) ${ }^{5}$ & WBGT & Mean: 14.74, Std. Dev.: 5.12 \\
\hline Apparent temperature $(\mathrm{AT})^{5}$ & AT & Mean: 7.67, Std. Dev.: 7.97 \\
\hline Physiologically equivalent temperature (PET) ${ }^{5}$ & PET & Mean: 7.52, Std. Dev.: 8.91 \\
\hline Universal Thermal Climate Index (UTCI) ${ }^{5}$ & UTCI & Mean: 1.70, Std. Dev: 14.07 \\
\hline Ice formation (Hour) $^{1}$ & Ice & Yes: $0.65 \%$, No: $99.35 \%$ \\
\hline Ice formation (Day) ${ }^{2}$ & Ice_D & Yes: $3.98 \%$, No: $96.02 \%$ \\
\hline Ice formation $(\mathrm{Fo} 7)^{3}$ & Ice_7 & Yes: $1.97 \%$, No: $98.03 \%$ \\
\hline Ice formation $(\mathrm{Fo} 30)^{4}$ & Ice_30 & Yes: $0.72 \%$, No: $99.28 \%$ \\
\hline \multicolumn{3}{|l|}{ Aesthetical components } \\
\hline Fog (Hour) ${ }^{1}$ & Fog & Yes: $2.42 \%$, No: $97.58 \%$ \\
\hline Fog (Day) ${ }^{2}$ & Fog_D & Yes: $15.92 \%$, No: $84.08 \%$ \\
\hline Fog $(\mathrm{Fo} 7)^{3}$ & Fog_7 & Yes: $4.09 \%$, No: $95.91 \%$ \\
\hline Fog $(\text { Fo30 })^{4}$ & Fog_30 & Yes: $0.30 \%$, No: $99.70 \%$ \\
\hline Cloud cover (in octants) $)^{5}$ & Cloud_cover & Mean: 5.36, Std. Dev.: 3.23 \\
\hline \multicolumn{3}{|l|}{ Physical components } \\
\hline Thunderstorm (Hour) ${ }^{1}$ & Thunder & Yes: $0.81 \%$, No: $99.19 \%$ \\
\hline${\text { Thunderstorm }(\text { Day })^{2}}^{2}$ & Thunder_D & Yes: $5.81 \%$, No: $94.19 \%$ \\
\hline Thunderstorm $(\mathrm{Fo} 7)^{3}$ & Thunder_7 & Yes: $3.54 \%$, No: $96.46 \%$ \\
\hline Thunderstorm $(\mathrm{Fo} 30)^{4}$ & Thunder_30 & Yes: $0.76 \%$, No: $99.24 \%$ \\
\hline Snow (Hour) ${ }^{1}$ & Snow & Yes: $1.08 \%$, No: $98.92 \%$ \\
\hline Snow (Day) ${ }^{2}$ & Snow_D & Yes: $3.14 \%$, No: $96.86 \%$ \\
\hline Snow $(\mathrm{Fo} 7)^{3}$ & Snow_7 & Yes: $1.56 \%$, No: $98.44 \%$ \\
\hline Snow $\left(\right.$ Fo30) ${ }^{4}$ & Snow_30 & Yes: $0.65 \%$, No: $99.35 \%$ \\
\hline Sunshine duration (in 0.1 hour) (Hour) ${ }^{5}$ & Sunshine & Mean: 3.24, Std. Dev.: 3.96 \\
\hline Sunshine duration (in 0.1 hour) (Day) ${ }^{6}$ & Sunshine_D & Mean: 24.63, Std. Dev.: 29.57 \\
\hline Precipitation duration (in 0.1 hour) (Hour) ${ }^{5}$ & Precip_dur & Mean: 0.74, Std. Dev.: 2.27 \\
\hline Precipitation duration (in 0.1 hour) (Day) ${ }^{6}$ & Precip_dur_D & Mean: 10.60, Std. Dev.: 20.35 \\
\hline Precipitation amount (in $0.1 \mathrm{~mm}$ ) (Hour) ${ }^{5}$ & Precip_amo & Mean: 0.92, Std. Dev.: 4.93 \\
\hline Precipitation amount (in $0.1 \mathrm{~mm}$ ) (Day) ${ }^{6}$ & Precip_amo_D & Mean: 13.71, Std. Dev.: 35.03 \\
\hline Precipitation $(\mathrm{Fo} 7)^{3}$ & Precip_7 & Yes: $1.35 \%$, No: $98.65 \%$ \\
\hline \multicolumn{3}{|c|}{${ }^{2}$ Weather condition occurred during the recorded hour. } \\
\hline \multicolumn{3}{|c|}{${ }^{2}$ Weather condition occurred earlier the day of recording or during the recorded hour. } \\
\hline \multicolumn{3}{|c|}{${ }^{3}$ Weather condition is first occurrence of this weather condition in 7 days (Fo7). } \\
\hline \multicolumn{3}{|c|}{${ }_{5}^{4}$ Weather condition is first occurrence of this weather condition in 30 days (Fo30). } \\
\hline \multicolumn{3}{|c|}{5 Hourly value } \\
\hline \multicolumn{3}{|c|}{${ }^{6}$ Daily amount/duration of the weather condition until (and including) the recorded hour. } \\
\hline
\end{tabular}

\section{METHODOLOGY}

To achieve the main objective of this study, namely, the assessment of the variation in daily travel behaviour with weather, two MNL-GEE regression models were constructed: one for modelling the effect of weather conditions on trip motive and one to assess the effect of weather on modal choice. In essence, the MNL-GEE model extends the classical multinomial logit (MNL) model by explicitly taking into account correlated responses. Recall that the MNL model is a generalisation of the logistic regression model for cases where the dependent variable has more than 2 categories. Graphically, this corresponds to the prediction of the leaves of the regression trees displayed in Figure 2. In this study, commuting was chosen as the reference category in the trip-purpose model, whereas in the modal 
choice model, car use was chosen as the reference category. For a more elaborate methodological discussion, the reader is referred to Appendix A.

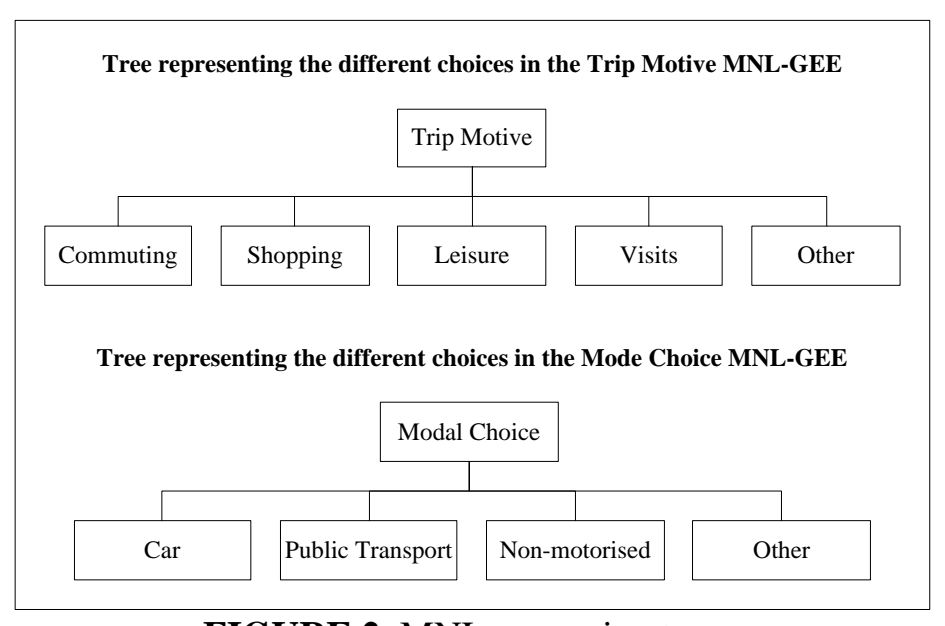

FIGURE 2 MNL regression trees.

A particular modelling aspect that needs attention is the potential problem of multicollinearity, i.e. the correlation among the explanatory variables. This correlation is especially high among the different thermal indices, as they all measure thermal comfort. This is confirmed by the calculation of Cronbach's alpha, which is a measure for the average correlation of a set of items. When considering, AT, ET, WBGT, PET and UTCI, this coefficient equals 0.95 , indicating an extremely high intercorrelation. Therefore, to avoid problems of multicollinearity, only a single thermal index should be included in the analysis. To determine which of the thermal indices should be incorporated, Cramer's contingency coefficient, a measure of association, was calculated. Cramer's V ranges between 0 (no association) and 1 (maximum association). The thermal index with the highest association with the response variable (being the trip motive / mode choice model) was chosen. For both the trip motive and the modal choice model this was PET. To diagnose the final models for multicollinearity, Variance Inflation Factors (VIFs) were calculated. All values were below 3, and thus below the critical threshold value of 4 , indicating that there was no serious problem of multicollinearity.

Notice that in the above discussion HI was not included in the calculation of Cronbach's alpha. Consideration of the four heat indices altogether would result into a negative Cronbach's alpha value, meaning that the four indices do not measure the same concept (thermal comfort). This is confirmed by the fact that $\mathrm{HI}$ is only valid for air temperatures above $20^{\circ} \mathrm{C}$ (Blazejczyk et al., 2012). Therefore, it was decided not to consider HI for the analysis.

\section{Results}

\subsection{Results for the Trip Motive Model}

The first model that was estimated was the MNL-GEE model for predicting trip motive. Recall that commuting (work/school) trips were defined as the reference trip motive. The correlation parameter alpha (estimated value of 2.06, standard error of 0.02) in this model was highly significant (p-value < 0.001 ), underscoring the importance of using a methodological framework that explicitly takes into account such correlations.

Table 4 summarises the results of the tests of the significance of the various sociodemographic and weather variables considered. This table shows that a multitude of sociodemographics play significant roles. In addition, the table shows that twelve weather variables affect the trip motive and thus the type of activity that is carried out, namely the thermal components physiologically equivalent temperature and ice formation, the aesthetical components fog (both in terms of occurrence during the hour of making the trip and occurrence during the day until the moment of the trip) and cloud cover, and the physical components related to the presence of thunder, sunshine duration and the amount and duration of precipitation. Consequently, the weather variables that are not 
presented in this table do not have a significant impact, as only the significant variables (at the 5\% level) were retained in the final models.

TABLE 4 Wald Statistics for Type 3 GEE Analysis of Trip Motive

\begin{tabular}{|c|c|c|c|}
\hline Parameter & DF & Chi $^{2}$ & P-value \\
\hline Intercept & 4 & 2164.67 & $<.0001$ \\
\hline \multicolumn{4}{|l|}{ Socio-demographics } \\
\hline Age & 4 & 607.85 & $<.0001$ \\
\hline Gender & 4 & 226.13 & $<.0001$ \\
\hline Education & 4 & 47.87 & $<.0001$ \\
\hline Professional status & 4 & 537.57 & $<.0001$ \\
\hline Income & 8 & 38.53 & $<.0001$ \\
\hline Driving license & 4 & 140.22 & $<.0001$ \\
\hline Household size & 4 & 388.39 & $<.0001$ \\
\hline Degree of urbanisation (residence) & 16 & 99.97 & $<.0001$ \\
\hline \multicolumn{4}{|l|}{ Trip-related attributes } \\
\hline Time of day & 4 & 967.68 & $<.0001$ \\
\hline \multicolumn{4}{|l|}{ Weather variables } \\
\hline PET & 4 & 223.48 & $<.0001$ \\
\hline Ice_D & 4 & 14.10 & 0.0070 \\
\hline Fog & 4 & 15.92 & 0.0031 \\
\hline Fog_D & 4 & 17.91 & 0.0013 \\
\hline Cloud_cover & 4 & 156.16 & $<.0001$ \\
\hline Thunder_D & 4 & 22.31 & 0.0002 \\
\hline Sunshine & 4 & 501.72 & $<.0001$ \\
\hline Sunshine_D & 4 & 1573.18 & $<.0001$ \\
\hline Precip_dur_D & 4 & 161.55 & $<.0001$ \\
\hline Precip_amo & 4 & 14.74 & 0.0053 \\
\hline Precip_amo_D & 4 & 24.68 & $<.0001$ \\
\hline Precip_7 & 4 & 24.29 & $<.0001$ \\
\hline
\end{tabular}

The parameter estimates for the significant variables in the trip motive model are shown in Table 5. Recall that commuting was selected as the reference motive, thus the parameter estimates correspond to the three remaining motives. Note that the parameter estimates of the intercepts and the socio-demographics are omitted from this table, as the main focus is on the interpretation of the weather effects.

Table 5 Parameter Estimates for the Trip Motive MNL-GEE

\begin{tabular}{|c|c|c|c|c|c|c|c|c|}
\hline \multirow{2}{*}{ Parameter } & \multicolumn{2}{|c|}{ Shopping } & \multicolumn{2}{|c|}{ Leisure } & \multicolumn{2}{|c|}{ Visits } & \multicolumn{2}{|c|}{ Other } \\
\hline & Est. & S.E. & Est. & S.E. & Est. & S.E. & Est. & S.E. \\
\hline \multicolumn{9}{|c|}{ Trip-related attributes } \\
\hline Time of day (peak) & -0.4563 & 0.0255 & -0.4463 & 0.0237 & -0.3592 & 0.0245 & 0.2500 & 0.0280 \\
\hline \multicolumn{9}{|l|}{ Weather Variables } \\
\hline PET & 0.0206 & 0.0019 & -0.0146 & 0.0018 & -0.0102 & 0.0020 & 0.0083 & 0.0022 \\
\hline Ice_D & 0.0497 & 0.0751 & -0.1719 & 0.0807 & -0.0967 & 0.0942 & 0.3088 & 0.1087 \\
\hline Fog & -0.3013 & 0.0923 & -0.1457 & 0.0711 & -0.0770 & 0.1038 & 0.0616 & 0.0845 \\
\hline Fog_D & 0.0834 & 0.0413 & 0.1187 & 0.0443 & -0.0983 & 0.0521 & -0.1070 & 0.0608 \\
\hline Cloud_cover & 0.0449 & 0.0048 & -0.0254 & 0.0044 & -0.0154 & 0.0047 & 0.0271 & 0.0057 \\
\hline Thunder_D & 0.0212 & 0.0687 & 0.2092 & 0.0667 & 0.1576 & 0.0677 & -0.2233 & 0.0846 \\
\hline Sunshine & 0.0728 & 0.0042 & -0.0324 & 0.0038 & -0.0452 & 0.0041 & 0.0068 & 0.0049 \\
\hline Sunshine_D & -0.0046 & 0.0005 & 0.0098 & 0.0004 & 0.0141 & 0.0005 & -0.0034 & 0.0006 \\
\hline Precip_dur_D & 0.0009 & 0.0010 & 0.0063 & 0.0011 & 0.0129 & 0.0011 & -0.0010 & 0.0013 \\
\hline Precip_amo & 0.0027 & 0.0019 & -0.0067 & 0.0027 & 0.0054 & 0.0023 & 0.0013 & 0.0020 \\
\hline Precip_amo_D & -0.0004 & 0.0006 & -0.0011 & 0.0008 & -0.0035 & 0.0008 & 0.0012 & 0.0008 \\
\hline Precip_7 & -0.3426 & 0.1069 & 0.1123 & 0.1065 & -0.5467 & 0.1631 & 0.1845 & 0.1425 \\
\hline
\end{tabular}


With respect to the thermal component, one could derive that each ${ }^{\circ} \mathrm{C}$ increase in PET corresponds to a $2.08 \%(=\exp (0.0206)-1)$ increase in the odds of making shopping trips, a $0.83 \%$ increase in the odds of making other trips, a $1.45 \%$ decrease in the odds of making leisure trips and a $1.01 \%$ decrease in the odds of making visit trips. Recall that all these odds are formulated in comparison to carrying out commuting trips, as the latter alternative is the reference category in the model. Concerning ice formation, one could observe that ice formation earlier on the day decreases the likelihood to make leisure trips, whereas it increases the likelihood to make other trips.

With regard to the aesthetical components, one could depict that the presence of fog during the start hour of the trip reduces the odds of making shopping trips by $26.01 \%$ and reduces the odds of making leisure trips by $13.56 \%$, whereas it does not significantly influence visit and other trips. In contrast, the occurrence of fog earlier on the day was found to significantly increase the odds of shopping and leisure trips and to decrease the odds of visits trips. This provides evidence that the presence of fog induces travellers to postpone their non-mandatory such as shopping and leisure trips until the fog disappeared, as also reported by Cools et al. (2010b). The results pertaining to cloud cover indicate that each octant increase in cloud cover corresponds to a $4.59 \%$ increase in the odds of shopping trips and a $2.75 \%$ increase in the odds of other trips, whereas the odds of leisure and visit trips are reduced by $2.51 \%$ and $1.53 \%$, respectively.

Concerning the physical aspect of weather, one could notice that the occurrence of thunder earlier on the day increases the odds of making a leisure trip by $23.27 \%(=\exp (0.2092)-1)$, increases the odds of a visit trip by $17.07 \%$ and decreases the odds of other trip purposes (including bring/get activities, touring) with $20.01 \%$. When the parameter estimates related to sunshine duration are explored, one could observe that the signs of the effect of the sunshine duration during the hour of departure are opposing the signs of the effect of the accumulative daily sunshine duration. Sunny weather during the hour of departure seems to especially favour shopping trips, whereas the accumulative sunshine duration has a positive effect on the odds of making leisure and visit trips. These opposite signs are a clear indication that the effect of weather observed during a short period before the departure of the trip does not trigger the same behavioural changes as weather observed over a longer period before the trip. Expectations about the weather conditions occurring later that day, for instance created by weather forecasts, play an important role in this regard (see e.g. Cools and Creemers, 2013).

Finally, one could observe that precipitation affects daily travel behaviour in different ways. The precipitation amount during the hour departure significantly decreases the odds of making leisure trips, whereas it increases the odds of visit trips. Besides, the accumulative precipitation duration and amount affect especially visit trips. Lastly, if the precipitation occurred for the first time in 7 days, one could observe a considerable drop in the odds of making shopping and visit trips.

\subsection{Results for the Modal Choice Model}

The second model that was estimated was the MNL-GEE model for predicting modal choice. Recall that car trips were defined as the reference modal choice. Again, the correlation parameter alpha (estimated value of 3.70, standard error of 0.05 ) underscores the importance of using an approach that considers the correlations among the alternatives.

Table 6 presents the results of the tests of significance of the various socio-demographic, triprelated and weather variables considered. This table shows that a multitude of socio-demographic variables playing a significant role in model choice. Moreover, trip motive and trip distance also play a role in modal choice. Note that trip distance and modal choice were not incorporated in the MNL-GEE model for predicting trip motive, as it was perceived that trip motive is a higher-order decision-making attribute, i.e., that trip motive is decided at an earlier stage in the trip planning process than the modal choice and the trip distance. The latter in particular is considered to be the result of the decision made concerning the activity location.

The table shows that five weather variables have a significant effect on the modal choice. These five variables are the physiologically equivalent temperature, the occurrence of thunder, sunshine duration and precipitation duration, and variable indicating whether or not precipitation occurred for the first time in 7 days. These results suggest that the variables related to the remaining 
weather variables (snow, ice formation, cloud cover and fog) do not significantly influence modal choice, as only the significant variables (at the 5\% level) were retained in the final models.

The parameter estimates for the significant trip-related attributes and weather variables are provided in Table 7. As for the trip motive model, the parameter estimates of the intercepts and sociodemographic variables are omitted from this table.

TABLE 6 Wald Statistics for Type 3 GEE Analysis of Modal Choice

\begin{tabular}{|l|r|r|r|}
\hline Parameter & DF & $\mathbf{C h i}^{\mathbf{2}}$ & P-value \\
\hline Intercept & 3 & 751.06 & $<.0001$ \\
\hline Socio-demographics & 3 & 90.05 & $<.0001$ \\
\hline Age & 3 & 36.53 & $<.0001$ \\
\hline Gender & 3 & 106.51 & $<.0001$ \\
\hline Education & 3 & 52.39 & $<.0001$ \\
\hline Professional status & 6 & 42.12 & $<.0001$ \\
\hline Income & 3 & 523.18 & $<.0001$ \\
\hline Driving license & 3 & 28.82 & $<.0001$ \\
\hline Household size & 12 & 432.86 & $<.0001$ \\
\hline Degree of urbanisation (residence) & 12 & 1153.79 & $<.0001$ \\
\hline Trip-related attributes & 3 & 2377.33 & $<.0001$ \\
\hline Motive & 3 & 9.92 & 0.0192 \\
\hline Distance & \multicolumn{5}{|l|}{} \\
\hline Time of day & 3 & 50.96 & $<.0001$ \\
\hline Weathervariables & 3 & 8.28 & 0.0406 \\
\hline PET & 3 & 8.70 & 0.0335 \\
\hline Thunder_30 & 3 & 44.35 & $<.0001$ \\
\hline Sunshine & 3 & 15.87 & 0.0012 \\
\hline Precip_dur_D &
\end{tabular}

With respect to the trip-related attributes, the results show that public transport is the most likely mode to be used for commuting trips. This can be explained by the fact that residential location choice is often related to accessibility to public transport (Zhao, 2013). In addition, the use of nonmotorised modes is also stimulated by commuting trips. The share of these modes is also higher in the case of leisure trips. These stimulation effects are consistent with the biking culture in the Netherlands (Pucher and Buehler, 2008). Public transport use was found to increase with trip distance, as was the use of other modes, whereas trip distance has a diminishing effect on non-motorised modes. The latter finding can be explained by the fact that when trip distance increases, the realism of choosing these modes as alternative decreases.

Table 7 Parameter Estimates for the Modal Choice MNL-GEE

\begin{tabular}{|c|c|c|c|c|c|c|}
\hline \multirow{2}{*}{ Parameter } & \multicolumn{2}{|c|}{ Public transport } & \multicolumn{2}{|c|}{ Non-motorized modes } & \multicolumn{2}{|c|}{ Other } \\
\hline & Est. & S.E. & Est. & S.E. & Est. & S.E. \\
\hline \multicolumn{7}{|l|}{ Trip-related attributes } \\
\hline Motive: Commuting & 1.3430 & 0.0963 & 0.7426 & 0.0436 & 0.5949 & 0.1335 \\
\hline Motive: Leisure & -0.0606 & 0.1138 & 0.6237 & 0.0413 & 0.4953 & 0.1286 \\
\hline Motive: Other & -0.0312 & 0.1239 & -0.0053 & 0.0481 & 0.7321 & 0.1425 \\
\hline Motive: Shopping & 0.2313 & 0.0905 & -0.0543 & 0.0366 & 0.1218 & 0.1232 \\
\hline Distance & 0.0022 & 0.0001 & -0.0296 & 0.0008 & 0.0012 & 0.0001 \\
\hline Time of day (peak) & 0.0680 & 0.0314 & -0.0019 & 0.0159 & -0.1266 & 0.0555 \\
\hline \multicolumn{7}{|l|}{ Weather variables } \\
\hline PET & -0.0094 & 0.0034 & 0.0092 & 0.0017 & 0.0197 & 0.0053 \\
\hline Thunder_30 & -0.4456 & 0.3457 & -0.4217 & 0.1729 & 0.3938 & 0.4827 \\
\hline Sunshine & 0.0067 & 0.0046 & 0.0060 & 0.0024 & 0.0034 & 0.0071 \\
\hline Precip_dur_D & 0.0012 & 0.0014 & -0.0038 & 0.0006 & -0.0016 & 0.0027 \\
\hline Precip_7 & 0.2447 & 0.2406 & 0.4554 & 0.1189 & 0.1591 & 0.3866 \\
\hline
\end{tabular}

Italics indicate parameters significant at the $5 \%$ level 
With regard to the thermal component of weather, one could observe that a $0.1^{\circ} \mathrm{C}$ increase in physiologically equivalent temperature reduces the odds of using public transport by $0.94 \%$, whereas it increases the odds of using non-motorised modes and other modes by $0.92 \%$ and $1.99 \%$, respectively. With respect to the physical components of weather, one could note that the first occurrence of thunder in 30 days limits the use of non-motorised modes, evidenced by a decrease in the odds to use these modes by $33.40 \%$. Good weather in terms of sunshine duration increases the odds of using non-motorized modes. Similarly, the negative sign by the daily accumulative effect of precipitation indicates that good weather increases the likelihood of choosing non-motorized modes. This confirms the general expectation that these modes are more extensively used during favourable weather conditions as these modes are typically non-sheltered.

\section{DISCUSSION AND CONCLUSIONS}

This study contributes to the existing literature on the effect of meteorological variability on transport behaviour by pinpointing the effects of various weather conditions on daily activity participation, approximated by trip purposes, and by assessing the impacts of weather conditions on modal choices using revealed preference data. The estimates of the selected socio-demographic variables and triprelated attributes have a logical interpretation and are consistent with results reported in the international literature. Yagi and Mohammadian (2008) for instance, emphasised the importance of trip distance, income, gender, age and the possession of a driving license as factors that contribute to modal choice.

The estimates of the weather variables indicate that, depending on which travel attribute is considered, other factors might play a role. Nonetheless, in correspondence to the literature on holiday travel (Çalışkan et al., 2012; Matzarakis et al., 2013), the thermal component, as well as the aesthetical component and the physical component of weather play a significant role in daily travel as is evidenced by the significance of these variables in the models presented in this paper. These results confirm earlier findings based on stated preference data, in which fog, precipitation and temperature are reported to trigger behavioural changes (Cools et al., 2010b). Moreover, it should be underlined that these different weather components are also reported to significantly affect traffic intensity (Cools et al., 2010a).

In addition to the different weather components, the seasonality of the weather conditions, reflecting seasonal habituation effects, as well as the occurrence of several weather types earlier the day of reporting, played a significant role in explaining variability in daily travel behaviour. This underlines the importance of incorporating seasonal effects in the analysis of meteorological impacts, as is underlined in the investigation of holiday travel (Ridderstraat et al., 2014).

An unexpected finding was that snow does not play a role. Cools et al. (2010b) and Van Berkum et al. (2006) emphasised the relevance of this variable. Nonetheless, this finding is not worrisome and can be explained by the relative low frequencies of this weather event in the study area, as evidenced by Table 1 .

With respect to the data, the matching between the weather data and the trip diary records should be noted. The weather data stem from weather stations, which are point sources, whereas the information is applied to larger areas, despite the fact that weather is often a very volatile and local phenomenon. This extrapolation in space can potentially lead to errors in the determination of the weather conditions at a specific location and thus for a specific trip. However, weather measurements primarily rely on point sources, as highlighted by Chapman and Thornes (2011) in their research on the spatial resolution of weather measurements in the context of reliable road weather decision support systems. In addition to being aggregated in space, weather data are also aggregated in time. Although hourly data are the most detailed level at which weather data are commonly available, the weather can vary greatly within an hour. Taking into account these two challenges with respect to the data, some caution is advised in generalising the findings of the study. Incorporation of unofficial weather information (e.g., in the activity diaries) might be valuable in further research in this regard.

It is important to integrate the identified impacts of weather on travel demand modelling frameworks because this will help to achieve higher accuracy and more realistic traffic forecasts, which in turn will allow policy makers to make better long-term and short-term decisions to achieve 
various political goals, such as progress towards a sustainable transportation system. Further research in this regard should emphasise the role of weather conditions and activity-scheduling attributes.

\section{ACKNOWLEDGEMENTS}

The authors would like to thank the editor and reviewer for their useful comments, especially with regard to the inclusion of thermal indices in the analysis.

\section{APPENDIX A: MNL-GEE METHODOLOGY}

To achieve the main objective of this study, namely, the assessment of the variation in daily travel behaviour with weather, two MNL-GEE regression models were constructed: one for modelling the effect of weather conditions on trip motive and one to assess the effect of weather on modal choice. In essence, the MNL-GEE model extends the classical multinomial logit (MNL) model by explicitly taking into account correlated responses by means of a marginal effect model that is estimated using generalised estimating equations (GEEs). In marginal effect models, the mean function is modelled directly, and the correlation structure is regarded as a nuisance parameter. It is important to consider this correlation structure, as the characteristics of the trips made by the same person are most likely correlated. That is, the trip characteristics of one trip are likely to be correlated to the characteristics of other trips made by the same person.

To estimate the values of the parameters of the MNL-GEE model, the procedure suggested by Kuss and McLerran (2007) was followed: the MNL-GEE model was specified as a marginal model by reorganising the response vector in a way that enabled it to be fitted as a multivariate binary model. The original variable $Y_{i j}$ corresponding to trip motive or modal choice is now written as an $((R-1) \times 1)$ vector $Y_{i j}{ }^{*}$ of binary variables $Y_{i j r}{ }^{*}$ such that $Y_{i j}=2, \ldots, R$ results in $Y_{i j}{ }^{*}=1$ in column $r$ and 0 anywhere else. In the case of $Y_{i j}=1$ (reference category), $Y_{i j}{ }^{*}=0$ all $R-1$ columns. In this paper, $R$ equals to 5 in the trip motive model ( 5 trip motives; commuting, shopping, leisure, visits, other), and 4 in the modal choice model (4 transportation modes; car (driver/passenger), public transport, non-motorized modes, other) and respectively commuting and car (driver/passenger) were used as the reference category.

Let $Y_{i}^{*}=\left(Y_{i 1}^{*}, \ldots, Y_{i n_{1}}^{*^{\prime}}\right)$ denote the $\left(n_{i}(R-1) \times 1\right)$ response vector for the $i$-th cluster with expectation $\pi_{i}^{*}$ and covariance matrix $V_{i}^{*}$. This covariance $V_{i}^{*}$ is a "double-block" diagonal matrix where the $(R-1) \times(R-1)$-block for $(r, r)$ on the "inner" block of the main diagonal of $V_{i}^{*}$ is a multinomial covariance matrix for the $j$-th observation in the $i$-th cluster and the remaining elements on the "outer" block specify the covariance between two different observations $(j, j)$ in the $i$-th cluster. Formally, this amounts to

$$
V_{i}^{*}=\operatorname{cov}\left(Y_{i j r}^{*}, Y_{i j^{\prime} r^{\prime}}^{*}\right)= \begin{cases}\pi_{i j r}^{*}\left(1-\pi_{i j r}^{*}\right) & \text { if } j=j^{\prime}, r=r^{\prime} \\ -\pi_{i j r}^{*} \pi_{i j r^{\prime}}^{*} & \text { if } j=j^{\prime}, r \neq r^{\prime}, \\ \frac{\operatorname{corr}\left(Y_{i j r}^{*}, Y_{i j^{\prime} r^{\prime}}^{*}\right)}{\sqrt{\pi_{i j r}^{*}\left(1-\pi_{i j r}^{*}\right) \pi_{i j^{\prime} r^{\prime}}^{*}\left(1-\pi_{i j^{\prime} r^{\prime}}^{*}\right)}} & \text { if } j \neq j^{\prime}\end{cases}
$$

where the first two lines of Equation 2 correspond to the "inner" block of $V_{i}^{*}$, the third line to the "outer" block, and $\pi_{i j r}{ }^{*}=E\left[Y_{i j r}{ }^{*}=1\right]$. It should be noted that the third line does not constitute a circular definition. Instead, $\operatorname{corr}\left(Y_{i j r^{*},}, Y_{i j^{\prime} r^{\prime}}{ }^{*}\right)$ must be given a working correlation pattern in the analysis (Miller et al., 1993). The model is then given by the following equation:

$$
\log \left(\frac{\pi_{i r}^{*}}{1-\pi_{i r}^{*}}\right)=\theta_{r}^{*}+X_{i j}^{\prime} \beta_{r}^{*},
$$

where $\pi_{i r}{ }^{*}$ denotes the expectation of all elements of $Y_{i}^{*}$ belonging to response category $r, \theta_{r}{ }^{*}$ a vector of parameters to be estimated and $X_{i j}$ the vector of explanatory variables. Note that there is no reference to a random effect in the model equation. 
Akaike's information criterion (AIC) is often used as a model selection criterion because it has some important advantages. First, it takes into account how well the model describes the data, and second, it punishes models that contain more parameters (Kutner, 2005). Moreover, the AIC value is based on the log-likelihood and thus has the asymptotic properties of the maximum likelihood estimator (MLE). Because GEE is not likelihood based, we do not have a likelihood function in this context. Moreover, the GEE estimator has different asymptotic properties than the MLE. This makes it impossible to determine the AIC value. Pan (2001) proposed an extension of the AIC criterion that is applicable in the context of GEE. He replaced the log-likelihood value in the AIC criterion with the quasi-likelihood value and also modified the penalty term. This modified AIC criterion is called the "quasi-likelihood under independence criterion," abbreviated as the QIC criterion. As with AIC, the model with the smallest QIC value is preferred.

\section{REFERENCES}

Ahmed M, Abdel-Aty M, Yu R (2012) Assessment of interaction of crash occurrence, mountainous freeway geometry, real-time weather, and traffic data. Transport Res Rec 2280:51-59

Blazejczyk, K (2010) BioKlima - Universal tool for bio-climatic thermophysiological studies. Institute of Geography and Spatial Organization, Polish Academy of Sciences, Warsaw. http://www.igipz.pan.pl/Biokli-ma-zgik.html [Accessed 15 April 2014]

Blazejczyk, K, Epstein, Y, Jendritzky G, Staiger, H, Tinz, B (2012). Comparison of UTCI to selected thermal indices. Int J Biometeorol 56:515-535

Böcker L, Dijst M, Prillwitz J (2013a) Impact of everyday weather on individual daily travel behaviours in perspective: a literature review. Transport Rev 33:71-79

Böcker L, Prillwitz J, Dijst M (2013b) Climate change impacts on mode choices and travelled distances: a comparison of present with 2050 weather conditions for the Randstad Holland. J Transp Geogr 28:176-185

Bos IDM, Van der Heijden RECM, Molin EJE, Timmermans HJP (2004) The choice of park and ride facilities: an analysis using a context-dependent hierarchical choice experiment. Eviron Plann A 36:1673-1686

Çalışkan O, Çiçek I, Matzarakis A (2012) The climate and bioclimate of Bursa (Turkey) from the perspective of tourism Theor Appl Climatol 107:417-425

Chapman L, Thornes JE (2011) What spatial resolution do we need for a route-based road weather decision support system? Theor Appl Climatol 104:551-559

Cools M, Moons E, Wets G (2010a) Assessing the impact of weather on traffic intensity. Weather Clim Soc 2:60-68

Cools M, Moons E, Creemers L, Wets G (2010b) Changes in travel behaviour in response to weather conditions. Transport Res Rec 2157:22-28

Cools M, Creemers L (2013) The dual role of weather forecasts on changes in activity-travel behaviour. J Transp Geogr 28:167-175

Habtemichael F, de Picado Santos L, El Faouzi NE (2012) Parameters of time headway distribution as performance indicators of motorway traffic and driver behaviour: comparison of good and adverse weather conditions. Transport Res Rec 2272:152-160

Hart MA, Sailor DJ (2009) Quantifying the influence of land-use and surface characteristics on spatial variability in the urban heat island. Theor Appl Climatol 95:397-406

Hammond DS, Chapman L, Thornes JE (2010) Verification of route-based road weather forecasts. Theor Appl Climatol 100:371-384

Heinen E, Maat K, van Wee B (2011) Day-to-day choice to commute or not by bicycle. Transport Res $\operatorname{Rec} 2230: 9-18$

Heinen E, Maat K, van Wee B (2013) The effect of work-related factors on the bicycle commute mode choice in the Netherlands. Transportation 40:22-43

Hooper E, Chapman L, Quinn A (2013) The impact of precipitation on speed-flow relationships along a UK motorway corridor. Theor Appl Climatol. Doi: 10.1007/s00704-013-0999-5

Jung S, Qin X, Noyce DA (2012) Injury severity of multivehicle crash in rainy weather. J Transp EngASCE 138:50-59 
Khattak AJ, De Palma A (1997) The impact of adverse weather conditions on the propensity to change travel decisions: A survey of Brussels commuters. Transport Res A-Pol 31:181-203

Kuss O, McLerran D (2007) A note on the estimation of the multinomial logistic model with correlated responses in SAS. Comput Meth Prog Bio 87:262-269

Kusumastuti D, Hannes E, Janssens D, Wets G, Dellaert BGC (2010) Scrutinizing individuals' leisureshopping travel decisions to appraise activity-based models of travel demand. Transportation 37:647-661

Kutner MH, Nachtsheim CJ, Neter J, Li W (2005) Applied linear statistical models. McGrawHill/Irwin, New York

Kwon T, Fu L, Jiang C (2013) Effect of winter weather and road surface conditions on macroscopic traffic parameters. Transport Res Rec 2329:54-62

Lam WHK, Shao H, Sumalee A (2008) Modeling impacts of adverse weather conditions on a road network with uncertainties in demand and supply. Transport Res B-Meth 42:890-910

Matzarakis A, Rammelberg J, Junk J (2013) Assessment of thermal bioclimate and tourism climate potential for central Europe - the example of Luxembourg. Theor Appl Climatol 114:193-202

Matzarakis A, Rutz F, Mayer H (2010) Modelling radiation fluxes in simple and complex environments: basics of the RayMan model. Int J Biometeorol 54: 131-139

Pan W (2001) Akaike's Information Criterion in Generalized Estimating Equations. Biometrics $57: 120-125$

Projectteam Mon (2008) Mobiliteitsonderzoek Nederland 2008: het databestand. Ministerie van Verkeer en Waterstaat/ Rijkswaterstaat.

Pucher J, Buehler R (2008) Making Cycling Irresistible: Lessons from the Netherlands, Denmark, and Germany. Transport Rev 28:495-528

Ridderstraat J, Oduber M, Croes R, Nijkamp P, Martens P (2014) Impacts of seasonal patterns of climate on recurrent fluctuations in tourism demand: Evidence from Aruba. Tourism Manage 41:245-256

Rowan E, Evans C, Riley-Gilbert M, Hyman R, Kafalenos R, Beucler B, Rodehorst B, Choate A, Schultz P (2013) Assessing the sensitivity of transportation assets to extreme weather events and climate change. Transport Res Rec 2326:16-23

Sabir M, Ommeren JV, Koetse M, Rietveld P (2011) Adverse weather and commuting speed. Netw Spat Econ 11:701-712

Sluijter R, Leenaers H, Camarasa M (2011) Bosatlas van het klimaat. Noordhoff Uitgevers BV, Nederland

Thomas T, Jaarsma R, Tutert B (2013) Exploring temporal fluctuations of daily cycling demand on Dutch cycle paths: the influence of weather on cycling. Transportation 40:1-22

Van Berkum E, Weijermars W, Hagens A (2006) The impact of weather on urban travel demand in the Netherlands. In proceedings of EWGT2006 International Joint Conferences, Bari, Italy.

Van Cauwenberg J, Van Holle V, Simons D, Deridder R, Clarys P, Goubert L, Nasar J, Salmon J, De Bourdeaudhuij I, Deforche B. (2012) Environmental factors influencing older adults' walking for transportation: a study using walk-along interviews. Int J Behav Nutr Phys Act 9:1-11

Venner MJ, Zamurs J (2012) Increased maintenance costs of extreme weather events: preparing for climate change adaptation. Transport Res Rec 2292:20-28

Vlahogianni EI, Karlaftis MG, Orfanou FP (2012) Modeling the effects of weather and traffic on the risk of secondary incidents. J Intell Transport Syst 16:109-117

Wong BYM, Faulkner G., Buliung R, Irving, H (2011) Mode shifting in school travel mode: examining the prevalence and correlates of active school transport in Ontario, Canada. BMC Public Health 11:618

Yagi S, Mohammedian A (2008) Policy simulation for new BRT and area pricing alternatives using an opinion survey in Jakarta. Transp Plan Technol 31:589-612

Zhao Y, Sadek AW, Fuglewicz D (2012) Modeling the impact of inclement weather on freeway traffic speed at macroscopic and microscopic levels. Transport Res Rec 2272:173-180

Zhao P (2013) The impact of the built environment on individual workers' commuting behaviour in Beijing. Int J Sustain Transp 7:389-415

Zick CD, Hanson H, Fan JX, Smith KR, Kowaleski-Jones L, Brown BB, Yamada I (2013) Re-visiting the relationship between neighbourhood environment and BMI: an instrumental variables 
approach to correcting for residential selection bias. International journal of behavioural nutrition and physical activity 10:27 